\title{
Dealing with prejudice
}

Alan O'Rourke University of Sheffield

\begin{abstract}
Few of us are free of all prejudices, however subtle and subconscious, and they may affect both patient care and teaching. Here I use reflection about a patient with HIV infection, from the points of view of two doctors caring for him and the patient himself, to explore prejudice against lifestyles that are considered "dangerous". The paper then goes on to discuss research about physicians' attitudes to such cases, the teaching of ethics in a clinical environment and the need to support junior medical staff.

(Fournal of Medical Ethics 2001;27:123-125)
\end{abstract}

Keywords: Prejudice; HIV infections; professional-patient relationships

\section{The incident-my viewpoint}

"I'm not going in there: I'm not taking blood from him, and I'm not re-siting his drip!" Thus declared the house officer about a young man with HIV and an atypical pneumonia, when I was a senior house officer (SHO) on an infectious diseases unit. We were on call together, when the patient was particularly ill, requiring several changes to his intravenous antibiotics and several sets of blood cultures, which I did. The house officer was busy elsewhere and was normally competent and hard-working.

We had another HIV patient, whose parents were blissfully ignorant of both his condition and his sexual orientation. For six months, he was a frequent ward attender, popular with the staff (he did not want to be an inpatient unless it was essential). He died on the ward while I was on holiday, and the secretary, who also knew him, said: "It was horrible when he died: they had to send up a sealed body bag from the mortuary!"

I subsequently used these episodes for reflection on a critical incident in a master's course. One useful technique we were taught, was to re-write events from the viewpoint of the other participants.

\section{The incident-the house officer's viewpoint}

"We get paid bugger all for the hours we work Some of my friends with arts degrees have got wonderful jobs in journalism and advertising. They don't work sixty hours a week, they don't do on call, and they coasted through university and skived most of their lectures. I don't mind working hard: everyone works as a team here, and we all pull our weight. Some of my mates get no support from their SHOs, and have really nasty consultants, but cover is good here and the consultants are really friendly.
But, I don't see why I should put my life on the line. I'm young and healthy, and I intend to stay that way. Alan's older, okay, only a few years, but he knows more about HIV and how to protect yourself. He's been here a few months and he's had a couple of goes at the membership of the Royal College of Physicians exam. Anyway, I think he likes the hands on stuff. But, I am not risking getting some horrible disease from a needlestick. It's not that I'm a gay-basher, I've got some really good friends who are gay, and I'm all for toleration and equalising the age of consent, but this guy is probably a junkie, and that's plain stupid."

The incident-the patient's viewpoint

"Why am I in this little cubicle on my own? It's like you've got the plague. They all take their white coats off before they come in, and they put on those smelly plastic gloves before they touch me. Then they rush over and put all the needles and things in that plastic bin under the window. Yellow, what a colour, like the old quarantine flags. Unclean, unclean! We are the new lepers! They can be really scared sometimes, I can almost hear the sigh of relief when they get all the needles into the bin, like 'I'm safe now, I won't prick myself and end up like you!' I know a lot about my disease: I'm concerned, but I want to know more. I think I know more than the youngest one, only comes when they're all here, maybe just a student, learning the ropes. I know about as much as the other one, Adrian or something, but I wish the boss would come along on his own just once for a one-to-one chat and tell me what's really going on. It's funny the old "healing touch," not that I fancy any of them or anything, but there is something in human contact, but without those gloves!"

We were advised to wear gloves when doing any procedures with "category 3 " patients (ie HIV and hepatitis B cases) that might involve contact with "bodily fluids". The whole ward was in cubicles and there was no day-room, and we used to hang our white coats up outside each room to reduce cross infection, but I don't think he was aware of these bits of ward routine.

\section{Initial reflection}

I said nothing at the time to the house officer, but should I have raised the issue in a non-judgmental way, discussing the risks, and how they could be minimised by thoughtful practice? How would I have dealt with an underlying bias or homophobia that came to light? Should I have just said: "It's your job, you're paid for it"? To avoid accusations of 
personal cowardice ("Don't tell me what to do you're as scared of scratching yourself with a soiled needle as I am!'”), maybe sharing his care would have been a compromise. Towards the patient, I was polite, even deferential, but I often felt uncomfortable, because he asked pertinent questions, that I could not answer. Also, in putting myself at greater risk of infection than was strictly necessary, were there any obligations to my partner? When a friend was a nursing student, her husband did not want her to nurse HIV patients. I was also aware that I was treating him differently, and I was more conscious of his condition, in the same way that I feel uncomfortable around physically and especially mentally handicapped people: how do you find out if they want help, or offer to help, without appearing condescending, or making it plain that you see them as having a problem coping?

\section{Some research}

I did some research on issues around ethics, attitudes to HIV patients, and supervision of junior staff. Many of the references were American, and some were up to ten years old. I was a bit shocked to find that American studies show that up to $23 \%$ of junior hospital staff would prefer not to care for AIDS patients if they had a choice ${ }^{1}$ : perhaps the American figures are influenced by the predominance of private practice, as AIDS patients seem a greater financial liability. Within these groups, there were finer distinctions: doctors seemed less generous to ex-intravenous drug abusers with AIDS than to homosexuals: the old Poor Law approach of dividing the destitute into "the deserving poor" and "the feckless". One article pointed out that in the pre-antibiotic era, health care staff did sometimes put themselves at direct risk in caring for patients with infectious diseases, and in some ways HIV has put fears of "contagion" back 50 years. ${ }^{1}$ When clinicians were given similar case studies, but told that some of the patients had AIDS, and some had leukaemia, the clinicians were less sympathetic to the AIDS patients and felt less able to discuss their illnesses with them. ${ }^{1}$

Up to $37 \%$ of the Americans felt that providing such care was "dangerous", 2 and some favoured segregation for AIDS patients and compulsory HIV testing of high-risk groups. ${ }^{3}$ One paper addresses the disrupting effect of wearing gloves on the therapeutic role of direct physical contact, in the doctorpatient relationship. ${ }^{4}$

So, reluctance to care for AIDS patients seems to have several causes:

- Fear of contracting AIDS, especially through needlestick injuries;

- Homophobia, dislike of drug users and other sub-cultures who embrace "dangerous" habits;

- Feeling that much of medical care for AIDS is futile, leading to cynicism.

However, the last two reasons apply to lots of other illnesses, such as many cancers, and heart disease in those who continue to smoke. Much acute health care is delivered by young, healthy and healthconscious doctors: how does this affect their attitudes to chronically sick patients, whose lifestyles may have exacerbated or caused their conditions? To some extent, these fears may be born out of ignorance, and the juniors feeling inadequately trained to care competently for HIV patients. Better training and more knowledge can improve confidence about managing such patients, reduce fear, and make practitioners more positive about treating HIV patients, and more rational in their use of precautions. ${ }^{5}$ In particular, those lacking training may overestimate the risk from certain procedures or incidents, and express unwarranted fears.

One paper suggested that house officers look for clinical skills, personality and teaching skills in selecting role models. ${ }^{7}$ What sort of role model did I present? As I had just failed the first part of the Royal College of Physicians entrance examination for the third time of asking, I did not feel very confident either as a teacher or as someone who set a professional example of how to manage one's career. It also seems that the way medical education in the UK is organised, most teaching hospital staff are selected more on clinical and academic grounds, than for their teaching skills.

Other authors suggest that ethical issues such as "living wills", consent to undergo treatment and decisions about withdrawal of care in the terminally ill, should be covered in the house officer year. Ethics teaching can be incorporated into case presentations, or delivered separately in seminars, but then it is sometimes delivered by non-clinicians (for example, theologians, or philosophers) who feel out of their depth dealing with technical medical issues. There is evidence that an ethics education programme in the house officer year, run by a physician but with input from other disciplines, can improve confidence in making ethical decisions. ${ }^{8}$ In many cases, the house officer year is still marked by a remarkable lack of feedback and support, ${ }^{9}$ and this sounds like the experience of my peers in the middle 1980s. One solution may be the use of a log book to record a personal learning plan, like those used by vocational trainees in general practice. ${ }^{10}$

\section{Conclusion}

I think there were two real issues here for me in this incident.

1. MY RELATIONSHIP WITH THE HOUSE OFFICER

In view of what I've read, this could have been an opportunity for teaching on ethics (obligation to provide un-biased high quality care), and clinical issues (minimising risk in caring for HIV patients; reasonable use of precautions). I should have provided an opportunity to voice and discuss fears, and negotiated a division of labour, rather than just taking over. I'm still not sure how easily I would have handled any biases or prejudices that might have been expressed. 
2. My RELATIONSHIP WITH THE PATIENT

I should have used gloves less frequently-for taking blood, but not for listening to his chest. I should have found out more about how he felt, and arranged for him to have some time with the consultant. I should have told him more about the ward routine and layout.

I learned some more general lessons:

- Education in ethics can improve confidence about making "difficult" decisions in a clinical situation. Introducing ethical dimensions into case presentations and ward work seems more effective than lectures.

- Junior staff need opportunities to voice their fears and ask for advice on matters other than issues of diagnosis and choice of best treatment. Their senior colleagues owe them something better than narrow technical instruction.

- I have become conscious of my feelings towards patients with diseases that the medical profession may regard as self-inflicted or at least lifestyle-related. Reliving the episode from the patient's viewpoint reminded me that patients do not always make "logical decisions" about their health; similarly doctors may be less than totally rational about using precautions, for instance gloves. Although members of the caring professions may think themselves the broad-minded product of an enlightened education, we must ensure that conscious or subconscious prejudices don't mean shorter shrift and less time for some of our patients than others. Rewriting the episode from others' viewpoints reminded me of Harper Lee's book, To Kill a Mocking Bird, ${ }^{11}$ where the story is presented by an intelligent but prejudice-free child. Her father has a dictum about "climbing inside someone's skin and walking around in it for a while to see how it feels". The book has a lot to say about how to view people as individuals, rather than as part of a stereotyped group.

- Even though I am no longer in clinical practice, I think my raised awareness of how we can be consciously or subconsciously biased will be useful (if not always comfortable!) in teaching students whose backgrounds and value systems are different from mine.

I wrote up this episode thinking of how the prejudices of the clinician can affect the quality of care we provide to certain minority groups. But, quality of care may also be influenced by prejudices that the patient may make explicit during the consultation. I suppose that here the sensitive clinician has either to adopt Voltaire's principle of free speech: "I disapprove of what you say, but I will defend to the death your right to say it"12 or, maybe go for the Christian dichotomy of hating the sin but loving the sinner.

While I was researching this paper, the British Medical fournal had a debate about how doctors feel about treating avowedly racist patients. ${ }^{13}$ I still think I might find myself feeling less generous to patients or students makes passing but blatant racist, ageist or sectarian comments than to those who merely choose to disregard "good advice".

\section{Acknowledgements}

My thanks to module tutors Professor Nigel Mathers and Gillie Bolton, both of Sheffield University Institute of General Practice for support and encouragement.

Alan O'Rourke, $M B C h B, M s c$, is a Lecturer at the Institute of General Practice and Primary Care, University of Sheffield.

\section{References}

1 Kelly JA, St Lawrence JS, Smith S, Hood HV, Cook DJ. Stigmatization of AIDS patients by physicians. American fournal of Public Health 1987;77:789-91.

2 Hayward RA, Shapiro MF. A national study of AIDS and residency training: experiences, concerns, and consequences. Annals of Internal Medicine 1991;114:23-32.

3 Shelley GA, Howard RJ. A national survey of surgeons' attitudes about patients with human immunodeficiency virus infections and acquired immunodeficiency syndrome. Archives of Surgery 1992; 127:206-11.

4 Linn LS, Kahn KL. Physician attitudes toward the "laying on of hands" during the AIDS epidemic. Academic Medicine 1989; 64:408-9.

5 Tesch BJ, Simpson DE, Kirby BD. Medical and nursing students' attitudes about AIDS issues. Academic Medicine 1990; 65:467-9.

6 Ficarrotto TJ, Grade M, Bliwise N, Irish T. Predictors of medi6 cal and nursing students' levels of HIV-AIDS knowledge and their resistance to working with AIDS patients. Academic Meditheir resistance to wo
cine 1990;65:470-1.

7 Wright S. Examining what residents look for in their role modWright S. Examining what residents look
els. Academic Medicine 1996;71:290-2.

8 Sulmasy DP, Marx ES. Ethics education for medical house officers: long term improvements in knowledge and confidence. fournal of Medical Ethics 1997;23:88-92

9 Garrud P. Counselling needs and experience of junior hospital doctors. British Medical fournal 1990;300:445-7.

10 Paice E, Moss F, West G, Grant J. Association of use of a log book and experience as a pre-registration house officer. British Medical fournal 1997;314:213-15.

11 Lee H. To kill a mocking bird. London: Pan Books, 1974.

12 Cohen JM, Cohen MJ. The new Penguin dictionary of quotations. Harmondsworth: Penguin, 1998: 443.

13 Selby M, Neuberger J, Easmon C, Gough P. Dealing with racist patients. British Medical fournal 1999;318:1129-31. 